\section{Anthropometric assessment of nutritional status in Brazilian pregnant women}

\author{
Patricia de Carvalho Padilha, ${ }^{1,2}$ \\ Elizabeth Accioly, ${ }^{2,3}$ Beatriz \\ Della Libera, ${ }^{2}$ Cristiane Chagas, ${ }^{2}$ \\ and Cláudia Saunders $2,3,4$
}

Suggested citation: Padilha PC, Accioly E, Libera BD, Chagas C, Saunders C. Anthropometric assessment of nutritional status in Brazilian pregnant women. Rev Panam Salud Publica. 2009;25(2):171-8

Key words: pregnancy, anthropometry, weight gain, methods, Brazil.

\footnotetext{
1 Pediatric Institute (IPPMG), Federal University of Rio de Janeiro (UFRJ), Rio de Janeiro, RJ, Brazil. Send correspondence and reprint requests to: Patricia de Carvalho Padilha, Rua Gramado 475, Bloco C, Apto. 202, Campo Grande, CEP 23050-090, Rio de Janeiro, RJ, Brasil; e-mail: paticpadilha@yahoo.com.br

2 Maternal and Child Health Research Group (GPSMI), Center for Micronutrient Research (NPqM), Josué de Castro Institute of Nutrition (INJC), UFRJ, Rio de Janeiro, RJ, Brazil.

3 Department of Nutrition and Dietetics, INJC/UFRJ, Rio de Janeiro, RJ, Brazil.

4 Maternity School, UFRJ, Rio de Janeiro, RJ, Brazil.
}

The World Health Organization (WHO) $(1,2)$ cites maternal anthropometric aspects and intake of adequate nutrients as determinants of fetal growth, demonstrating a close association with these parameters and weight and gestational age at birth. Anthropometric measurements, among the most frequently applied methods for assessing nutritional status in pregnant women, are recognized as effective tools in the prevention of perinatal morbi-mortality, the prognosis of child health, and the promotion of women's health (3), and have undergone considerable improvement over the past five decades (4). In addition, their easy application, low cost, and non-invasive nature reinforce their viability as a nutritional assessment method.

Several studies have shown an association between anthropometric indicators and pregnancy outcome. Both insufficient and excessive gestational weight gain are strongly associated with maternalfetal complications such as gestational diabetes, hypertensive pregnancy disorders (HPD), macrosomia, and low birth weight $(2,5-7)$. Moreover, excessive gestational weight gain is one of the conditions most strongly associated with postpartum weight retention and, consequently, postpartum obesity $(8,9)$.

Monitoring gestational nutritional status by taking anthropometric measurements is a promising means of optimizing fetal growth. It is well known that nutritional intervention focused on woman's health during the reproductive stage- not only in the preconception period but also during the prenatal period, and culminating in assistance to lactating woman-helps achieve adequate newborn nutritional status and is reflected in childhood health and nutritional conditions (2).

According to Coelho et al. (4), research focused on determining the best methodology for anthropometric assessment during pregnancy is a preoccupation of national and international health agencies and nongovernmental organizations, who justify such efforts as a means of ensuring adequate anthropometric assessment of the nutritional status of pregnant women.

This study surveys the available literature on anthropometric assessment of pregnant women and critically reviews the methodologies that have been recommended over the past five decades, focusing on their validation for applicability in prenatal care practice and incorporation into routine health services.

\section{Source of bibliographical data}

Available literature published between 1957 and 2007 was identified via MEDLINE ${ }^{\circledR}$ (Medical Literature Analysis and Retrieval System Online), LILACS (Latin American and Caribbean Health Sciences Literature Database), SciELO (Scientific Electronic Library 
Online), and other international health bibliographic databases. The search start date (1957) was selected based on the publication date of a classic study that provided the framework for some of the current methods for anthropometric assessment (10).

The selection criteria for this review were study design (cohort, case-control, or cross-sectional) and language (English, Spanish, or Portuguese). The inclusion criteria were 1) description of anthropometric methods applied to pregnant women worldwide, particularly in Brazil, over the past five decades; and 2) description of method specificity. Experimental studies and those in languages other than English, Spanish, or Portuguese, or only available in abstract format, were excluded.

While more than 3000 articles were selected, only 45 were included in the review. The terms adopted as English descriptors were weight gain, anthropometry, nutritional assessment, and pregnancy (ganho de peso, antropometria, avaliação nutricional, and gestação, and ganancia de peso, antropometría, diagnóstico nutricional and embarazo in Portuguese and Spanish respectively). The results are shown by method, country where the study was carried out, sample size $(n)$, and indicators analyzed.

\section{Use of anthropometric assessment methods}

In terms of anthropometric assessment, pregnancy is characterized as a brief observation period in which the anthropometric index undergoes rapid changes (11).

Conducting anthropometric measurements during the prenatal period is a routine practice. However, its actual effectiveness depends on the availability of services, the number of prenatal care visits, and women's consent to having their measurements taken.

Ensuring the most beneficial outcome requires the use of anthropometric assessment methods that help develop an effective and practical application instrument capable of predicting maternal and infant health conditions and allowing for adequate nutritional intervention during this period of high biological vulnerability (11).

Nonetheless, the use of anthropometric measurements in pregnancy to promote health and improve obstetric results-including maternal morbi-mortality indices, conditions at birth, and perinatal mortalityraises certain issues that underscore the need for validation of some of the practical aspects of the process as well as its universal applicability in normative terms (12-16). These issues include: water retention, which frequently causes edema; alteration in body composition; and postural, hormonal, and other physiological conditions of pregnancy (17) that are directly reflected in weight gain, the most common anthropometric measure used during pregnancy follow-up. Measurements of weight and height, and their associations, to produce pre-gestational Body Mass Index (BMI) indices, and (less commonly) the calculation of arm circumference and cutaneous folds, are also recommended in the anthropometric nutritional assessment of pregnant women (11).

\section{Various applications}

To examine relationships between maternal anthropometric measurements and infant birth-size indices, a cross-sectional study was conducted among 498 Zimbabwean pregnant women who delivered singleton infants. Women in the lowest quartile for midarm circumference were more likely to have a lowbirth-weight infant compared to women in the highest quartile. In addition, maternal mid-arm circumference was strongly related to infant birth-size indices, with each unit increase in maternal mid-arm circumference resulting in a 36.1-g increase in infant birth weight $(p<0.001)(18)$.

Optimal anthropometric indicators are those that prove most effective in identifying 1 ) changes in nutritional status, preferably at the beginning of and during pregnancy, and 2) changes resulting from public health interventions. They must also have sufficient sensitivity and specificity to adequately identify different categories of maternal nutritional status and predict risk of low birth weight and gestational complications such as diabetes (11).

Previous studies assessing the sensitivity and specificity of weight-gain indicators according to IOM recommendations indicate that these are the only indicators more sensitive than specific as predictors of obstetric complications such as gestational diabetes (18).

Sensitivity, specificity, and the positive predictive value are determined according to the relationship between a risk factor and a determined result. Optimal indicators are those most useful in defining the magnitude of foreseen effects of a public health policy aimed at decreasing adverse results (11).

In a study of maternal anthropometry based on data collected from 1959 to 1989 and conducted by WHO (11) with the collaboration of research centers in various countries, the sensitivity and specificity of various indicators in relation to certain obstetric results were calculated. Sensitivity values varied from about 35 to $47 \%$ for pre-gestational weight (PGW) and low birth weight; 35 to $52 \%$ for PGW and small newborn for gestational age; 31 to $39 \%$ for pre-gestational BMI and prematurity; and 31 to $54 \%$ for PGW and prematurity, with specificity values above $70 \%$.

These data corroborate another meta-analysis study that assessed low birth weight determinant factors based on data collected from 1970 to 1984 and indicated a relative risk for intrauterine growth restriction (IUGR) of 1.27, 1.85, and 1.98, respectively, in women with height less than $158 \mathrm{~cm}$, PGW less than 54 $\mathrm{kg}$, and gestational weight gain less than $7 \mathrm{~kg}(19)$.

Abrams et al. (20) presented data on median maternal weight gain and birth weight in full-term newborns from research conducted during the early 1940s through 1983 that indicated an increase in the latter measure coincident with the growing disregard of gestational weight-gain restriction, which had previously been a common practice.

Over the last decade, public health experts have advocated revision of the objectives and indicators of 
anthropometric assessment during pregnancy and differentiation of risk indicators, benefits, and responses to interventions in the elaboration of reference values for the various phases of gestation. In practice, however, very few studies have taken all of these factors into account in formulating recommendations for the use of maternal anthropometry.

Assessment of nutritional status in pregnancy is extremely important at several levels. It is critical for monitoring and quantifying risk among specific populations for policy and program development. It is also an important adjunct in the management of women's health care due to its use in detecting abnormality in both the pre-reproductive and reproductive phases of women's lives. This type of assessment is therefore an important feature of antenatal care and must be feasible at the most peripheral level of the health care system.

\section{Historic evolution of methods}

Due to the current consensus on the importance of weight gain during pregnancy and the divergent opinions on recommended values, questions have emerged in the realm of maternal-infant care about which method of anthropometric assessment of pregnant women best predicts birth conditions as well as maternal health risks. As several risks have been acknowledged for both mother and newborn associated with inadequate maternal nutritional status, the elaboration and validation of anthropometric assessment methods must consider related outcomes for the mother as well as the newborn (4).

In recent years, the recommendations for adequate gestational weight gain have been controversial, and only a few longitudinal studies have focused on this issue (21). Through the first half of the last century, reduced weight gain was advocated as a means of preventing hypertensive pregnancy disorders (HPD), cesarean delivery, and maternal obesity. By the 1960s, however, the weight-gain restriction began to be questioned due to U.S. studies associating high infant mortality rates and low birth weight with reduced maternal weight gain. In 1970, a review of the evidence in the literature concluded that the obstetric practice of restricting maternal weight gain was associated with low birth weight, and this practice was therefore abolished in prenatal care (20).

The first proposed graphic representation of pregnant women's gestational weight gain appeared in 1961 when the Institute of Nutrition of Central America and Panama (Instituto de Nutrição do CentroAmérica e Panamá, INCAP) presented a model that aimed to show differences in maternal stature, including estimated weight gain, by gestational age, classifying pregnant women as "insufficient weight," "normal weight," and "overweight." The limitations of this model, which was applied across Central American countries as well as in several South American health services, include, among others, the fact that previous nutritional status was not considered $(11,22)$.
To overcome this limitation, Siqueira et al. (23) proposed modifying the INCAP model to consider the weight-height ratio and its normal variation, controlling for overweight or low-weight initial status for maternal stature. The revised model was tested with data from approximately 2000 pregnant women followed up in the city of São Paulo from pregnancy until delivery. Although this research did not result in modifications to the actual recommendations, it was used as a conceptual model with generally accepted but unvalidated cutoffs (minimum standards).

In the early 1980s, a guide for interpreting weight gain in the gestational period was proposed by Lechtig and Klein (24) in the form of a new graphic model based on percentile distribution of weight gain and its capacity to predict low birth weight risk. However, empirical evidence did not support its use.

In 1985, Chilean researcher Pedro Rosso proposed a method for monitoring gestational weight gain, based on a maternal weight-for-height adequacy curve derived from a cohort study of 262 pregnant women (mostly black and of Hispanic origin), to help predict birth weight (25). The Rosso curve was used for many years by the Brazilian public health services network as a tool for monitoring pregnant women's weight gain but was eventually replaced due to its low specificity, which had resulted in a low-weight positive diagnosis for pregnant women with adequate nutritional status (26).

The IOM recommendations were based on the concept of a weight-gain range determined by pre-gestational BMI, taking into consideration selected prenatal aspects, maternal nutritional status, and pregnancy course (fetal growth, birth weight, and retained postpartum weight). Subsequently, an extensive review of both the literature and epidemiological and clinical data, determinant of weight gain and their effects on maternal and infant health, was also carried out $(27,28)$. Classification cutoffs for pre-gestational nutritional status were established based on data from the Metropolitan Life Insurance Company, which distinguished low-weight and overweight values from the range of normality-approximately $90 \%$ and $120 \%$, respectively, of the ideal weight-for-height reference data (26). To determine the recommended weight-gain ranges during pregnancy, the IOM used data from the 1980 national survey of U.S. births of pregnancies from 39 to 41 weeks' gestation and birth weight between 3-4 $\mathrm{kg}$ as an operational definition of favorable obstetric results $(6,18,29-31)$.

The BMI (PGW / height ${ }^{2}$ ) is acknowledged as the most simple and useful index for assessing pre-gestational nutritional status because it is considered an indirect measure of energy storage $(11,27)$.

For more than a decade, the IOM recommended method $(27,28)$ has remained the most widely used, and its adoption by countries without a formulated recommendation of their own has been advocated $(11,32)$.

A direct correlation between maternal nutrition and newborn weight has been demonstrated through 
the application of IOM's recommended method for assessing perinatal risks. Based on these recommendations, several authors have concluded that gestational weight values can help predict birth conditions as well as optimal maternal nutritional status in the postpartum period $(14,33)$.

Nonetheless, there has been some criticism of various aspects of the IOM's recommended method, such as its wide range of recommended weight-gain values, and the fact that it was based on data from a developing-country population in which obesity is a relevant nutritional issue, and does not consider various conditions that could influence interpretation of risk, such as maternal age, parity, and preexisting diseases or gestational conditions $(11,34)$. However, as pointed out in the available literature, the IOMrecommended method has been associated with favorable obstetric results related to birth-weight outcome as well as maternal health $(14,20,33)$.

In a descriptive study that aimed to verify the accuracy of various methods of nutritional assessment in pregnant women, 433 adult puerperal women who received care at a public maternity hospital in Rio de Janeiro, Brazil, were assessed to predict low birth weight as an obstetric outcome. The most successful methods were those proposed by the $\operatorname{IOM}(27,28)$, adapted according to suggestions from the Brazilian Ministry of Health and taking into consideration PGW (pre-gestational weight) assessment and WHO's recommended BMI cutoff (1995) for adult women. In this study, the latter method proved the most effective for nutritional screening due to its association with low birth weight ( $\mathrm{OR}=4.10 ; 95 \% \mathrm{CI}=1.53-10.92)$ (35).

As pointed out by Groth (36), the fact that IOM recommendations for pregnant adolescents are currently based on the use of adult BMI categories for classifying pre-gestational BMI is another limitation of this methodology. The use of adolescent BMI percentiles may be more appropriate for this type of classification, and that for gestational weight gain, particularly for highlighting adolescents' higher risk of overweight and obesity. As suggested by Groth, the use of adolescent BMI percentiles to classify gestational weight gain may also result in better pregnancy outcomes.

The data on monthly maternal weight gain used to substantiate the IOM recommendations $(27,28)$ concur with WHO collaborative research indicating that in developing countries an increase of approximately $1.5 \mathrm{~kg} /$ month during the two last trimesters coincides with good obstetric results. WHO (11) acknowledges the need for investigating certain maternal characteristics that can influence gestational weight gain, such as height, parity, age, race, and pre-gestational BMI, to determine if some subgroups may benefit more from other methods. Regardless of how the recommendations are interpreted, the inclusion of low- and highrange limits for total gestational weight gain is fundamental (11).

Fescina (37) proposed the adoption of a new graphic model-the percentile curve for gestational weight gain adequacy associated with gestational age published by the Latin American Center of Perinatology (Centro Latinoamericano de Perinatología e Desarrollo Humano, CLAP) in Uruguay.

The abovementioned proposal was elaborated from a sample of 43 Uruguayan white, middle-class pregnant women considered to have good nutritional status (adequate PGW for height and tricipital cutaneous fold [TCF] during a pregnancy within normal limits and without history of anemia) from which weight measurements were taken weekly (for a total of 1003 measurements throughout the course of the study). The data was presented in the form of a graph plotting maternal weight gain per height by gestational age. When PGW was unknown, the use of maternal weight/height/gestational age values resulting from statistical extrapolations of this reference sample was recommended. The limitations inherent in the small sample size, and the weight gain recommendation $(8-16 \mathrm{~kg})$, independent of pre-gestational nutritional status, resulted in limited application of the reference data in both the academic world and in health care practice. In Brazil, however, the Ministry of Health (38) adopted this type of method in the 2000-2004 period.

In the late 1990s, Atalah et al. (39) proposed a new method for anthropometric assessment of pregnant women based on the gestational BMI from the 10 th to the 42 nd week and constructed from theoretical projections and population data from a prospective study conducted in Chile as an alternative approach to Rosso's curve (25). The study sample included 665 pregnant women in the 18-35 year age group, with parity less than 4, absence of chronic diseases that affect fetal growth, and prenatal care beginning before the 14th gestational week (39).

For the first few gestational weeks, the authors used the BMI criteria recommended by the Food and Agriculture Organization (FAO) and the Pan American Health Organization (PAHO) for non-pregnant women (low weight, $<20.0 \mathrm{~kg} / \mathrm{m}^{2}$; normal weight, between $20-24.9 \mathrm{~kg} / \mathrm{m}^{2}$; overweight, between $25-29.9$ $\mathrm{kg} / \mathrm{m}^{2}$; and obese, $\geq 30 \mathrm{~kg} / \mathrm{m}^{2}$ ). Based on the data on weight-gain tendency during pregnancy proposed by Thomson and Billewicz (10), a median weight gain of $600 \mathrm{~g}$ in the first trimester and a total increase of $20 \%$ of weight at the beginning of pregnancy were estimated as ideals for women with no weight deviances.

In a preliminary publication, the authors presented the new method as well as an analysis of the study sample's nutritional status during the initial prenatal period (in the form of a graph and a table), using classification categories based on gestational BMI estimated through a mathematical model. In that publication, the authors noted a decrease in maternal malnutrition, a significant increase in obesity, and a low-range low-weight rate of 5\% in the Chilean population. They also stated that the method would be validated via a prospective study aiming to assess the predictive value, sensitivity, and specificity of each nutritional classification category in relation to low 
birth weight, fetal macrosomia, pregnancy pathologies, and delivery complications (39).

In a publication on obesity and reproductive risk, Atalah and Castro (40) observed that the preferred indicator for nutritional diagnosis based on a multivariate analysis was gestational BMI, due to its significant association with the gestational complications that had been analyzed (such as diabetes and arterial hypertension), compared to the weight-heightratio index for gestational age. Although the authors did not present the actual results of the multivariate analysis, they did describe its contribution to the validation of their proposed index.

\section{Current methods in Brazil}

The methodology recently adopted by the Brazilian Ministry of Health, and already incorporated into the national monitoring instrument for the prenatal period $(26,41)$, is based on BMI assessment (pregestational and gestational) for determination of the recommended weight-gain range, similar to the methods recommended by $\operatorname{IOM}(27,28)$, and on assessment of BMI adequacy by gestational age, as proposed by Atalah et al. (39).

The Brazilian Ministry of Health's $(26,41)$ standard method for assessing pregnant women's nutritional status nationwide is a hybrid of two international standard methodologies that consider different indicators, which has proven somewhat controversial. Anthropometric assessment of pregnant women is based on BMI by gestational age, as proposed by Atalah et al. (39) in their graphic representation. The Ministry of Health $(26,41)$ defines the recommended inclination for each condition of each curve, taking into account the BMI-for-gestational age ranges. For example, for women with an initially low gestational BMI, the BMI-for-gestational age curve for the pregnancy period must have a steeper inclination than that of the curve delimiting the lower range of adequate nutritional status. In addition, after the pregnant women's first assessment, for either pre-gestational or gestational BMI, the use of total weight gain ranges for the first trimester and weekly gain ranges for the second and third gestational trimesters are recommended. The proposed weight-gain ranges are the same as those recommended by the IOM for the various pre-gestational BMI ranges $(27,28)$.

The current Brazilian methodology does not consider certain situations commonly observed in clinical practice. For example, initially, there was no predetermined weight-gain range for pregnant women with low stature, and the maternal low-stature cutoff had not been defined.

Because low stature is a marker of previous malnutrition, it is important to ensure adequate gestational weight for low-stature women (42). On the other hand, among these cases, excessive weight may be associated with cephalopelvica disproportion $(11,27,28)$.

A Brazilian study tested the hypothesis that the association between low stature $(<1.50 \mathrm{~m})$ and obesity observed in Brazilian women might be explained by weight gain in reproductive age. The major increase in BMI after pregnancy among low-stature women in urban areas, independent of parity, clearly demonstrates the risk of a higher gestational weight gain and its retention after delivery in the most developed areas in the country (42).

Analysis of the estimated weight gain through interpretation of the curve comprising the range of gestational BMI values suggested by the Brazilian Ministry of Health $(26,41)$ verifies the theory that weight gain may be excessive among those with initially low gestational weight and insufficient among those with initial gestational BMI situations classified as obesity. In addition, a lack of agreement was observed between gestational weight-gain ranges calculated in this way and the weight-gain ranges recommended by the $\operatorname{IOM}(27,28)$, which are included in the current Brazilian Ministry of Health recommendation $(26,41)$.

However, the study did not propose a maximum weight gain that might be considered safe and that should be recommended when pregnant women present excessive weight gain while still in the second or third gestational trimesters.

Moreover, although the recommended weight ranges are similar to those of the IOM, gestational BMI classification cutoffs are not shown, which raises many questions. Finally, the weight gain ranges for women with twin pregnancy and for adolescent pregnant women were not defined. A review of these issues would therefore be useful to facilitate procedure standardization in anthropometric assessment of pregnant women in prenatal routine health care in Brazil.

\section{New proposals worldwide}

Recently, Mardones and Rosso (43) presented a curve model for monitoring pregnant women's weight that has been adopted in health services in Chile. The proposal defined maternal nutritional status categories in early pregnancy (from week 10) according to the weight-for-height ratio, which was expressed in weight adequacy as well as in BMI percentiles, and took into account the high correlation among these indicators found in a previous study (44). The graphic representation was presented in two versions, both of which had gestational age as a horizontal axis. In the vertical axis, maternal weight was expressed in weight adequacy percentile for height measured in two ways: through the use of nomograms, and in terms of BMI. Both measures had specific cutoffs for BMI values and weight adequacy percentile for height attributed to each nutritional status category.

Weight/height limits in the abovementioned model, which classified women as low weight, normal, overweight, and obese, were built into a database including information on 1745 healthy, adult, nonsmoking/non-alcohol-consuming Chilean women with full-term pregnancy, a singleton fetus, and no obstetric complications capable of limiting fetal growth. 
Weight-gain recommendations were defined by nutritional status category and were proportional to maternal height. The recommendations for pregnant women with low weight were based on updated data from the Chilean population, while those for obese and overweight pregnant women were derived from data extrapolation.

In the Chilean study, according to the proposed model, low-weight women at full-term pregnancy had an increased risk of having newborns with birth weight $<3.000 \mathrm{~g}(\mathrm{OR}=1.73)$, whereas a higher risk of macrosomia ( $\geq 4.000 \mathrm{~g}$ ) was observed among those who were overweight $(\mathrm{OR}=1.31)$ or obese $(\mathrm{OR}=2.17)$. As noted by the authors of the study, validation studies must be conducted and recommendations from the scientific community must be implemented in order to derive the most universally applicable curve for gestational weight gain.

\section{Limitations}

Within a general context, the limitations of the proposed reference values for weight gain during pregnancy include the fact that they are derived from old studies with gestational age-assessment errors, performed decades ago among populations with 1) epidemiological characteristics distinct from those of current populations and 2) different ethnicities.

To decrease the effect of these limitations, Ochsenbein-Kölble et al. (16) aimed to create relevant reference data for weight gain based on BMI values in a large population of Caucasian women and using percentile distribution curves built by modern statistical methods. Curves designed for assessment of Asian and black women were also proposed. This study was considered innovative because it showed BMI percentile distribution in pregnancy derived from information obtained from a large sample of different ethnicities. The data demonstrated that parity and pregestational BMI had significant influence on weight gain and gestational BMI.
Unfortunately, the proportion of Asian and black women in the abovementioned study was too small to construct a curve of percentile distribution of this group data. Nonetheless, through statistical analyses, extrapolations were performed based on the standards for Caucasian women.

\section{Recommendations}

Considering the acknowledged importance of maternal nutritional status, including its impact on maternal and newborn health, and the prominent role of anthropometric indicators within the context of pregnancy, it is fundamental to adopt methods capable of 1) assessing risks for maternal health as well as birth conditions and 2) predicting maternal-fetal outcomes (Table 1).

It is therefore extremely important to select the method that is most appropriate for 1) optimal maternal anthropometric assessment, and clinical practice and 2) shows an association with a favorable obstetric result. Determination of this optimal methodology must be a priority in prenatal care quality assessment.

Studies designed to define reference values must be conducted among a specially selected population and have a longitudinal design and an appropriate sample size. In addition, the various risk indicators, benefits, and responses to interventions must be carefully considered in the elaboration of reference values for anthropometry in all periods of the biological cycle. Therefore, determining the sensibility and specificity values for the different methods is necessary to justify the selection of these methodologies and to direct their validation.

In addition, it should be noted that many gaps have not yet been filled regarding the best method for assessing the anthropometric nutritional status of pregnant women, and efforts must be made to solve this age-old issue.

Finally, whichever methodology is used, its limitations must be considered and other indicators must

TABLE 1. Summary of proposed indicators for use in different methods of anthropometric assessment among pregnant women

\begin{tabular}{|c|c|c|c|}
\hline Method & Country ${ }^{a}$ & Sample size $(n)$ & Indicators \\
\hline Maternal weight-for-height adequacy curve (25) & Chile & 262 & Weight/height/gestational age \\
\hline $\begin{array}{l}\text { Prediction of gestational weight gain ranges based on } \\
\text { pre-gestational weight (PGW) }(27,28)\end{array}$ & USA & $\begin{array}{l}\text { National survey of } \\
1980 \text { births, USA }\end{array}$ & Pre-gestational Body Mass Index (BMI) \\
\hline $\begin{array}{l}\text { Prediction of gestational weight gain ranges based on } \\
\text { gestational BMI (39) }\end{array}$ & Chile & 665 & Gestational BMI/gestational age \\
\hline $\begin{array}{l}\text { Use of percentile adequacy curve to verify gestational } \\
\text { weight gain ranges by gestational age (37) }\end{array}$ & Uruguay & 43 & Weight gain/gestational age \\
\hline $\begin{array}{l}\text { Prediction of gestational weight gain ranges based on } \\
\text { gestational and pre-gestational BMI }(26,41)\end{array}$ & Brazil & $\ldots b$ & Gestational and pre-gestational BMI \\
\hline $\begin{array}{l}\text { Use of weight adequacy percentile curve or BMI curve } \\
\text { for gestational age (43) }\end{array}$ & Chile & 1745 & $\begin{array}{l}\text { Weight adequacy percentile for height or BMI/ } \\
\text { gestational age }\end{array}$ \\
\hline
\end{tabular}

a Location of study.

b Data not available. 
be associated with the anthropometric data in the diagnosis of the nutritional status of pregnant women.

Acknowledgements. The authors would like to thank the following organizations for their support of this study: the Carlos Chagas Filho Foundation for the Support of Research in the State of Rio de Janeiro, Brazil (Fundação Carlos Chagas Filho de Amparo à Pesquisa do Estado do Rio de Janeiro, FAPERJ) and the National Council for Scientific and Technological Development (Conselho Nacional de Desenvolvimento Científico e Tecnológico, CNPq).

\section{SINOPSIS}

\section{Evaluación antropométrica del estado nutricional de embarazadas brasileñas}

Se revisó la literatura disponible publicada entre 1957 y 2007 sobre la evaluación antropométrica de embarazadas y se analizaron críticamente las metodologías recomendadas.
Las mediciones antropométricas constituyen el método más frecuentemente empleado debido a su reconocida utilidad para prevenir la morbimortalidad perinatal, predecir la salud del niño y promover la salud de la madre. Ha habido un intenso debate sobre el aumento óptimo de peso durante la gestación, que ha llevado a cambiar las recomendaciones nutricionales. Hasta la década de 1960 se sugería limitar el aumento de peso gestacional como una forma de evitar un resultado obstétrico desfavorable. Se reconoce que la metodología recomendada por el Instituto de Medicina (1990/1992) es la más aceptada en todo el mundo y ha servido de estándar de referencia en muchos estudios, sin embargo, también se presentan otros métodos (que utilizan modelos gráficos e indicadores basados en el índice de masa corporal y la tasa peso-altura gestacionales). Para contribuir a la salud materno-infantil se necesitan estudios que validen los indicadores de alteraciones nutricionales durante el embarazo y que tengan elevados valores de sensibilidad y especificidad con respecto a los desenlaces obstétricos indeseables, y determinar un estándar universal del aumento de peso durante la gestación.

Palabras clave: embarazo, antropometría, aumento de peso, métodos, Brasil.

\section{REFERENCES}

1. World Health Organization. Report of the advisory group meeting on maternal nutrition and low birth weight. Geneva: WHO; 2002.

2. World Health Organization. Promoting optimal fetal development: report of a technical consultation. Geneva: WHO; 2006.

3. Oliveira AF, Gadelha AM, Leal MC, Szwarcwald CL. Estudo da validação das informações de peso e estatura em gestantes atendidas em maternidades municipais no Rio de Janeiro, Brasil. Cad Saude Publica. 2004;20 Suppl 1: S92-100.

4. Coelho KS, Souza AI, Batista Filho M. Avaliação antropométrica do estado nutricional da gestante: visão retrospectiva e prospectiva. Rev Bras Saude Matern Infant. 2002;2(1):57-61.

5. Olson CM, Strawderman MS, Reed RG Efficacy of an intervention to prevent excessive gestational weight gain. Am J Obstet Gynecol. 2004;191(2):530-6.

6. Stotland NE, Haas JS, Brawarsky $P$, Jackson RA, Fuentes-Afflick E, Escobar GJ. Body mass index, provider advice, and target gestational weight gain. $\mathrm{Ob}$ stet Gynecol. 2005;105(3):633-8.

7. Mohanty C, Prasad R, Srikanth AR, Ghosh JK, Singh TB, Das BK. Maternal anthropometry as predictors of low birth weight. J Trop Pediatr. 2006;52(1): 24-9.

8. Lacerda EMA, Leal MC. Fatores associados com a retenção e o ganho de peso pós-parto: uma revisão sistemática. Rev Bras Epidemiol. 2004;7(2):187-200.
9. Ivyna Spinola CJ, Kac G. Determinantes da retenção de peso pós-parto segundo a cor da pele em mulheres do Rio de Janeiro, Brasil. Rev Panam Salud Publica. 2005;18(6):403-11

10. Thomson AM, Billewicz WZ. Clinical significance of weight trends during pregnancy. Br Med J. 1957;1(5013):243-7.

11. World Health Organization. Physical status: the use and interpretation of anthropometry. Report of a WHO Expert Committee. Technical Report Series No. 854. Geneva: WHO; 1995. 460 p.

12. Nucci LB, Duncan BB, Mengue SS, Branchtein L, Schmidt MI, Fleck ET. Assessment of weight gain during pregnancy in general prenatal care services in Brazil. Cad Saude Publica. 2001;17(6): 1367-74.

13. Brennand EA, Dannenbaum D, Willows ND. Pregnancy outcomes of First Nations women in relation to pregravid weight and pregnancy weight gain. J Obstet Gynaecol Can. 2005;27(10):936-44.

14. Kruger HS. Maternal anthropometry and pregnancy outcomes: a proposal for the monitoring of pregnancy weight gain in outpatient clinics in South Africa. Curationis. 2005;28(4):40-9.

15. Cedergren M. Effects of gestational weight gain and body mass index on obstetric outcome in Sweden. Int J Gynaecol Obstet. 2006;93(3):269-74.

16. Ochsenbein-Kölble N, Roos M, Gasser T, Zimmermann R. Cross-sectional study of weight gain and increase in BMI throughout pregnancy. Eur J Obstet Gynecol Reprod Biol. 2007;130(2):180-6.
17. McGanity WJ, Dawson EB, Hook JWV. Nutrição materna. In: Shils ME, Olson JA, Shike M, Ross AC. Tratado de nutrição moderna na saúde e na doença. São Paulo: Manole; 2003. p. 869-98.

18. Ogbonna C, Woelk GB, Ning Y, Mudzamiri S, Mahomed K, Williams MA. Maternal mid-arm circumference and other anthropometric measures of adiposity in relation to infant birth size among Zimbabwean women. Acta Obstet Gynecol Scand. 2007;86(1):26-32.

19. Kramer MS. Determinants of low birth weight: methodological assessment and meta-analysis. Bull World Health Organ. 1987;65(5):663-737.

20. Abrams B, Altman SR, Pickett KE. Pregnancy weight gain: still controversial. Am J Clin Nutr. 2000;71 Suppl 5: S123341.

21. Brynhildsen J, Sydsjö A, Norinder E, Selling KE, Sydsjö G. Trends in body mass index during early pregnancy in Swedish women 1978-2001. Public Health. 2006; 120(5):393-9.

22. Instituto de Nutrición Centro-America y Panamá. Evaluación del peso de la embarazada. Guatemala: INCAP; 1961.

23. Siqueira AAF, Ciari C Jr, Mattos ILB, Buralli KO, Batista Filho M, Schor N, et al. Aplicação de uma curva de ganho de peso para gestantes. Rev Saude Publica. 1977;11(2):288-93.

24. Lechtig A, Klein RE. Guia para interpretar la ganancia de peso durante el embarazo como indicador de riesgo de bajo peso al nacer. Bol Ofic Sanit Panam. 1980;89:489-95. 
25. Rosso P. A new chart to monitor weight gain during pregnancy. Am J Clin Nutr. 1985;41(3):644-52.

26. Ministério da Saúde (BR). Nota Técnica-Fevereiro de 2004 - Área Técnica de Saúde da Mulher e CGPAN - Coordenação Geral da Política de Alimentação e Nutrição/MS. Brasília (DF): MS; 2004.

27. Institute of Medicine. Nutrition during pregnancy. Washington: National Academy Press; 1990.

28. Institute of Medicine. Nutrition during pregnancy and lactation: an implementation guide. Washington: National Academy Press; 1992.

29. Jaeger AS, Perdamo EP, Rodríguez LS, García A. Riesgo de déficit nutricional antropométrico en el primer trimestre del embarazo. An Venez Nutr. 2002 15(1):25-30.

30. Hulsey TC, Neal D, Bondo SC, Hulsey T, Newman R. Maternal prepregnant body mass index and weight gain related to low birth weight in South Carolina. South Med J. 2005;98(4):411-15.

31. Marsoosi V, Jamal A, Eslamian L. Prepregnancy weight, low pregnancy weight gain, and preterm delivery. Int $\mathrm{J}$ Gynaecol Obstet. 2004;87(1):36-7.

32. Gibson RS. Principles of nutritional assessment. 2nd ed. New York: Oxford University Press; 2005.

33. Yekta Z, Ayatollahi H, Porali R, Farzin A. The effect of pre-pregnancy body mass index and gestational weight gain on pregnancy outcomes in urban care settings in Urmia-Iran. BMC Pregnancy Childbirth. 2006;6:15.

34. Johnson JW, Yancey MK. A critique of the new recommendations for weight gain in pregnancy. Am J Obstet Gynecol. 1996;174(1 Pt 1):254-8.

35. Padilha PC. Validação de metodologia de avaliação antropométrica de gestantes [dissertação]. Rio de Janeiro: Universidade Federal do Rio de Janeiro, Instituto de Nutrição Josué de Castro; 2006.

36. Groth S. Are the Institute of Medicine recommendations for gestational weight gain appropriate for adolescents? J Obstet Gynecol Neonatal Nurs. 2007;36(1): 21-7.

37. Fescina R. Nutrición materna y resultados perinatales. Clin Perinatol Argent. $1997 ; 4: 75-86$
38. Ministério da Saúde (BR). Assistência pré-natal: manual técnico. 3rd ed. Brasília (DF): MS; 2000

39. Atalah E, Castillo C, Castro R, Aldea A. Propuesta de un nuevo estándar de evaluación nutricional en embarazadas. Rev Med Chile. 1997;125(12):1429-36.

40. Atalah E, Castro R. Obesidad materna y riesgo reproductivo. Rev Med Chile. 2004;132(8):923-30.

41. Ministério da Saúde (BR). Pré-natal e puerpério: atenção qualificada e humanizada - manual técnico. Brasília (DF): MS; 2005.

42. Sichieri R, Silva CV, Moura AS. Combined effect of short stature and socioeconomic status on body mass index and weight gain during reproductive age in Brazilian women. Braz J Med Biol Res. 2003;36(10):1319-25.

43. Mardones F, Rosso P. A weight gain chart for pregnant women designed in Chile. Matern Child Nutr. 2005;1(2): 77-90.

44. Mardones F, Rosso P, Marshall G, Villarroel L, Bastías G. Comparación de dos indicadores de la relacion peso-talla en la embarazada. Acta Pediátr Esp. 1999; 57(11):501-6.

\section{La desnutrición en lactantes y niños pequeños en América Latina y el Caribe: alcanzando los objetivos de desarrollo del milenio}

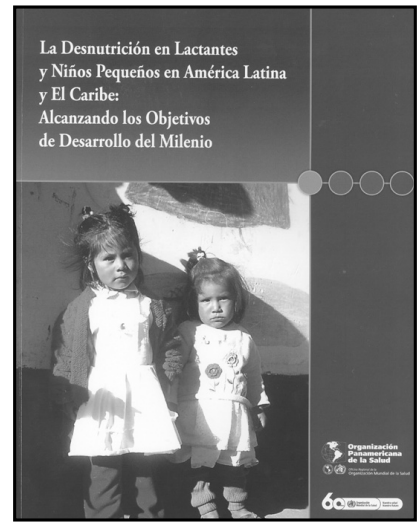

Adquiera esta publicación por medio de la librería en línea de la OPS: http://publications.paho.org; correo electrónico: paho@brightkey.net; Fax: (301) 209-9789; Oficina de país de la OPS/OMS

2008, 222 pp.

ISBN: 9789275332597

US\$ 22.00 en América

Latina y el Caribe/

US\$28.00 en el resto del mundo

Código: OT 201 